\title{
A descriptive study on health workforce performance after decentralisation of health services in Uganda
}

\author{
George William Lutwama', Janetta Hendrika Roos ${ }^{2^{*}}$ and Bethabile Lovely Dolamo²
}

\begin{abstract}
Background: Uganda, like many developing countries, is committed to achieving the Millennium Development Goals (MDGs) by 2015. However, serious challenges prove to hamper the attainment of these goals, particularly the health related MDGs. A major challenge relates to the human resources for health. The health system in Uganda was decentralised in the 1990s. Despite the health sector reforms, the services have remained significantly deficient and performance of health workers is thought to be one of the contributing factors. The purpose of this study was, therefore, to investigate the performance of health workers after decentralisation of the health services in Uganda in order to identify and suggest possible areas for improvement.
\end{abstract}

Methods: A cross-sectional descriptive survey, using quantitative research methods was utilised. A structured self-administered questionnaire was used to collect quantitative data from 276 health workers in the districts of Kumi, Mbale, Sironko and Tororo in Eastern Uganda. The health workers included doctors, clinical officers, professional nurses and midwives. The sample was selected using stratified random sampling. The data was analysed using SPSS version 18.0 and included both univariate and bivariate analysis. The results were presented in tabular and text forms.

Results: The study revealed that even though the health workers are generally responsive to the needs of their clients, the services they provide are often not timely. The health workers take initiatives to ensure that they are available for work, although low staffing levels undermine these efforts. While the study shows that the health workers are productive, over half (50.4\%) of them reported that their organisations do not have indicators to measure their individual performance. The findings indicate that the health workers are skilled and competent to perform their duties. In general, the results show that health workers are proficient, adaptive, proactive and client-oriented.

Conclusion: Although Uganda is faced with a number of challenges as regards human resources for health, the findings show that the health workers that are currently working in the health facilities are enthusiastic to perform. This may serve as a motivator for the health workers to improve their performance and that of the health sector.

Keywords: Health workers, Health workforce, Decentralisation, Performance, Health sector reforms

\section{Background}

One of the recent priorities meant to improve effectiveness of the health systems in Uganda is investment in human resources for health. The World Health Organization declared 2006 to 2015 a decade for the health workforce with high emphasis on the performance of human resources for health [1]. The World Health

\footnotetext{
*Correspondence: roosjh@unisa.ac.za

2Department of Health Studies, PO Box 392, Pretoria Unisa 0003, South Africa Full list of author information is available at the end of the article
}

Organization (WHO) defines the performance of health workers in terms of four dimensions that include responsiveness, productivity, competence and availability [1]. Hence, a performing health workforce is one that operates in ways that are reasonable, responsive and efficient to achieve favourable health outcomes [1]. The First Global Forum on Human Resources for Health held in 2008 in Kampala, issued a declaration that emphasises the need for equitable distribution as well as retention of skilled, productive and responsive health workers [2]. 
The public health system in Uganda has been decentralised to the districts since the health sectors reforms of the early 1990s [3-5]. The public health care system comprises the national hospital, regional referral hospitals and the district health care systems. The district health system comprises the district hospitals, health centres levels II, III, and IV and the village health teams (VHTs). The district hospital is the highest level of health care in the district. The district health care system is further subdivided into health sub-districts or a level IV health centre, which is aligned to a county or parliamentary constituency. Each county is sub divided into sub-counties. The health care services at this level are provided by a level III health centre. The sub-counties are further sub-divided into parishes or wards. The health care facility at this level is a level II health centre. This is the lowest level of health care facility that offers primary health care services. Lastly, parishes or wards are divided into villages. At this level there are VHTs, which are teams of local residents appointed to oversee the performance of health activities in their communities [6,7].

Despite the health sector reforms, the health services in Uganda have remained poor. The performance of health workers together with lack of adequate support from the central and local governments are believed to play a part in the stagnation and decline of some of the priority health indicators under the current Health Sector Strategic Plan (HSSP III) [7]. For instance, the proportion of children under one year who have received three doses of the pentavalent vaccine as per schedule reduced from $89 \%$ in the financial year 2005 to 2006 to $78 \%$ in 2007 to 2008 against the target of $87 \%$. The tuberculosis (TB) cure rate reduced from $73 \%$ to $68.4 \%$ during the same period. The proportion of sick children under age five years, who were seen by a health worker using the Integrated Management of Childhood Illnesses (IMCI) guidelines, reduced from $45 \%$ at baseline to $30 \%$ (2007 to 2008), below the target of $55 \%$. The outpatient new attendance rate stagnated at $80 \%$ for the past consecutive two years [8].

The Uganda press reports provide significant evidence regarding health worker performance problems in the districts, such as absenteeism, neglect of patients, drug pilferage and poor staff motivation. Evidence shows that the Minister of Health in Uganda once blamed decentralisation as the cause for poor delivery of health service in the country [9]. As a result of the deterioration of the health services, the President of Uganda wrote a letter to the Minister of Health in April 2008 demanding an explanation for health sector failures [10]. Whatever the case, the inadequate performance of individual health workers leads to poor health sector performance. It was, therefore, necessary to investigate the performance of the health workforce after decentralisation to identify the root cause of the problems.

\section{Objective}

The objective of this study was to investigate the performance of health workers after decentralisation of health services in Uganda in order to identify areas for improvement. Specifically, the study aimed at examining the performance based on the WHO dimensions of availability, productivity, competence and responsiveness. The study also aimed at identifying the behaviours of health workers that facilitate or hinder their performance.

\section{Methods}

The study was a cross-sectional and descriptive survey using quantitative research methods. The study population comprised these cadres of health workers: doctors, clinical officers and professional nurses working in health facilities in the Kumi, Mbale, Sironko and Tororo districts. To ensure representativeness and avoid bias, stratified random sampling was used $[11,12]$. Each district constituted a stratum. Within each district the sample was further stratified by the profession and type of health facility where they work. Using the lists of health workers obtained from the district health officers of the respective districts, a sample was randomly drawn from each stratum. A total of 331 health workers representing approximately $40 \%$ of the target population were included in the final sample. Of these, $83.4 \%(n=276)$ completed and returned the questionnaires.

A structured self-administered questionnaire was used to collect data concerning the dimensions of performance as well as the individual behaviours for performance. The questionnaire was based on a five-point Likert scale (where 1 = strongly disagree; 2 = disagree; 3 = undecided; $4=$ agree and 5 = strongly agree). Four questions elicited information about individual behaviours for performance with a number of sub-items as follows; proficiency behaviour (five items); adaptive behaviours (four items); proactive behaviours (four items) and client orientation behaviours (ten items). There were also four questions about the dimensions of performance as follows: availability (ten items); responsiveness (nine items); productivity (six items) and competence (nine items). The questionnaires were in English, which is the official working language in Uganda.

The pre-testing of the questionnaire was done at two levels. The first level involved seven experts in the field of study and the second level was with twelve experienced health workers (seven professional nurses and midwives, three clinical officers, and two medical doctors). These health workers were selected using convenience sampling from the hospitals of Kumi and Mbale. 
Results from the pre-test assisted with minor modifications in the wording of some of the questionnaire items. Following the pre-test and modifications, the first author (GWL) together with the trained research assistants delivered the questionnaires, a consent form and a letter explaining the reasons for conducting the study to the respondents. This was implemented from April 2010 to June 2010. The questionnaires were left with the respondents and collected within two weeks to allow them ample time to complete. Overall, the time for completing the questionnaire ranged from 30 to 45 minutes.

\section{Data analysis}

The returned self-administered questionnaires were cross-checked for completeness, coded and entered into a computer using the Statistical Package for Social Sciences (SPSS) version 18.0. The data were cleaned and analysed using the same version. For the purposes of the data presentation and interpretation, the categories 'strongly disagree' and 'disagree' were combined together to represent 'disagree'. Similarly, 'strongly agree' and 'agree' were combined to represent 'agree'. The results were presented in tabular form. Statistical analysis was done using both univariate and bivariate statistics. Bivariate analysis using Spearman rho correlation was used to determine association between two variables. Spearman rho correlation ( $r s)$ was used mainly where the data were based on the ordinal scale and, were therefore, not normally distributed [13]. The internal consistency of the scales was assessed using Cronbach's alpha $(\alpha)$ and ranged from 0.76 to 0.91 . The average alpha $(\alpha)$ was found to be 0.84 , which was adequate [14].

External validity was ascertained by way of stratified random sampling, and obtaining a correct composition and adequate sample size. Furthermore, the researcher collected data from all levels of health facilities including hospitals and health centres. Internal validity was ensured by constructing questionnaire items based on the study objective and extensive literature review, as well as voluntary participation of the health workers.

\section{Ethical considerations}

Ethical clearance was obtained from the Research and Ethics Committee at the Department of Health Studies of the University of South Africa; the Uganda National Council for Science and Technology (UNCST); and the Institutional Review Board of Mbale regional hospital. In the field, permission to collect data was obtained from the district officials, hospital medical superintendents and heads of the health sub-districts. Informed written consent was obtained from all respondents and their privacy was respected at all levels. The respondents were informed of their freedom to withdraw from the study at any time or not to answer any specific questions.
Confidentiality was maintained by protecting data collected from unauthorised access and the respondents remained anonymous.

\section{Results and discussion \\ Characteristics of the respondents}

The majority of respondents $(63.8 \%)$ were female and aged between 30 and 49 years (62.4\%); 74.6\% were either professional nurses or midwives, $18.5 \%$ were clinical officers and $6.9 \%$ were medical doctors. Most respondents (53.6\%) held diplomas. The majority of respondents (73.6\%) had more than five years of professional experience. Of the respondents, $56.9 \%$ were working in health centres (levels II, III, IV) while $43.1 \%$ were hospital based. As many as $59.8 \%$ health workers were working in rural areas. With regard to district of work, $38.4 \%$ were from Mbale, 23.6\% from Tororo, 19.9\% from Kumi and $18.1 \%$ from Sironko (see Table 1).

\section{Dimensions for measurement of performance of health workers}

The performance of health workers was measured using four dimensions namely responsiveness, availability, productivity and competence.

\section{Responsiveness of health workers}

Table 2 shows that all respondents (100.0\%) know what is expected of them. Most health workers (89.9\%) agreed that their clients are always satisfied with their services. The majority of the respondents (79.7\%) indicated that they get professional support to improve their performance. A total of $70.3 \%$ health workers indicated that they clearly know who they serve and many of them (69.9\%) are always willing to address the clinical and emotional demands of their clients. As many as $59.4 \%$ health workers agreed that the stakeholders are satisfied with the health workers' cooperation and the quality of service they provide. However, as many as $40.6 \%$ health workers indicated that clients were not satisfied with the quality of service they receive and $30.4 \%$ of respondents indicated that the clients were not satisfied with the level of cooperation they get from the health workers. Half of the respondents (50\%) indicated that rarely do the stakeholders complain about individual health workers, 30.1\% were undecided and $19.9 \%$ disagreed. It is, however, noted that $60.1 \%$ of the respondents disagreed that the patients were satisfied with the timeliness of the services, while $10.1 \%$ were uncertain.

Generally, from their own point of view, the health workers demonstrated satisfactory levels of service and responsiveness towards their clients. However, from their own point of view, the services that health workers provide are not timely. Health workers must demonstrate the ability and willingness to understand and 
Table 1 Characteristics of the respondents $(n=276)$

\begin{tabular}{lll}
\hline Demographic characteristics & Number & Percentage (\%) \\
\hline Gender & & \\
\hline Female & 176 & 63.8 \\
\hline Male & 100 & 36.2 \\
\hline Age, years & & \\
\hline 20 to 29 & 50 & 18.1 \\
\hline 30 to 39 & 115 & 41.7 \\
\hline 40 to 49 & 57 & 20.7 \\
\hline 50 to 59 & 54 & 19.6 \\
\hline 60 and above & 0 & 0.0 \\
\hline Current profession & & \\
\hline Medical doctor & 19 & 6.9 \\
\hline Clinical officer & 51 & 18.5 \\
\hline Registered nurse/midwife & 111 & 40.2 \\
\hline Enrolled nurse/midwife & 95 & 34.4 \\
\hline
\end{tabular}

\begin{tabular}{lll}
\hline Highest qualification & & \\
\hline Doctoral degree & 2 & 0.7 \\
\hline Master's degree & 4 & 1.4 \\
\hline Postgraduate certificate/diploma & 5 & 1.8 \\
\hline Bachelor's degree & 23 & 8.3 \\
\hline Diploma & 148 & 53.6 \\
\hline Certificate & 94 & 34.1 \\
\hline
\end{tabular}

Years of experience in health profession

\begin{tabular}{lll}
\hline 0 to 5 & 73 & 26.4 \\
\hline 6 to 10 & 68 & 24.6 \\
\hline 11 to 15 & 43 & 15.6 \\
\hline 16 to 20 & 26 & 9.4 \\
\hline 21 and above & 66 & 23.9
\end{tabular}

\begin{tabular}{lll}
\hline Type of health facility & & \\
\hline Hospital & 119 & 43.1 \\
\hline Health centre IV & 56 & 20.3 \\
\hline Health centre III & 80 & 29.0 \\
\hline Health centre II & 21 & 7.6 \\
\hline District of work & & \\
\hline Kumi & 55 & 19.9 \\
\hline Mbale & 106 & 38.4 \\
\hline Sironko & 50 & 18.1 \\
\hline Tororo & 65 & 23.6 \\
\hline Location of health facility & & \\
\hline Urban & 111 & 40.2 \\
\hline Rural & 165 & 59.8 \\
\hline
\end{tabular}

address both the clinical and emotional needs of their clients $[15,16]$. This study revealed that health workers were not providing timely services. This can be attributed to organisational constraints such as the low staffing levels, heavy workload, poor work flow structures and probably lack of some essential drugs and equipment necessary for performance [17]. It is essential that health workers are responsive to the demands of the communities they serve. This allows for a more holistic approach to health service provision, taking into consideration both the technical aspects and client satisfaction, thereby guaranteeing quality [18].

\section{Availability of health workers}

Most of the health workers (90.2\%) indicated that their health facilities have attendance registers that are completed by all staff. Similarly, $90.2 \%$ of health workers agreed that they put in much effort when they are on duty. Approximately ninety percent $(89.9 \%)$ of the health workers indicated that they are always available when needed. A total of $60.1 \%$ indicated that they are always present at work during the official working hours and also agreed that their organisations have clear retention policies. As many as $59.8 \%$ agreed that the staff attendance in their organisations was good, however, 40.2\% disagreed. There were mixed views in the responses from the health workers concerning patients' waitingtimes. A total of $40.6 \%$ of health workers agreed that waiting-times were short, while $39.5 \%$ disagreed and 19.9\% were uncertain (see Table 3).

A large proportion of health workers (80.1\%) disagreed that the rural facilities are as well staffed as the urban ones. Fifty percent of the health workers disagreed that their health facilities have adequate numbers of staff to deliver the services, $39.9 \%$ agreed and $10.1 \%$ were undecided. There were also mixed views among health workers concerning the workload. As many as $40.2 \%$ health workers indicated that the workload at their health facilities is not manageable while $39.5 \%$ stated that the workload was manageable and $20.3 \%$ were undecided (see Table 3).

The results of this study demonstrate that health workers try their best to be present at work. The reported high rate of disagreement among health workers regarding adequacy of staffing (Table 3) may probably explain high workload and long patients' waiting-times [17]. It is however, important to note that availability of health workers on its own cannot directly improve the health outcomes unless there is effective drug supply, functioning facilities and good clinical practice [19]. A well performing health workforce is a significant component of a strong health system that together with other social determinants can improve the health status of the population. As the numbers of health workers drop, the ability of systems to deliver health services also reduces $[1,20]$. Hence, the maldistribution of health workers between rural and urban health facilities as reported by the health workers in this study (Table 3), could affect the quality of health care and waiting-times may be longer [21]. 
Table 2 Items concerning the responsiveness of health workers $(\mathbf{n}=\mathbf{2 7 6})$

\begin{tabular}{|c|c|c|c|c|c|c|c|c|}
\hline \multirow[t]{2}{*}{ Item description } & \multicolumn{2}{|c|}{ Disagree } & \multicolumn{2}{|c|}{ Undecided } & \multicolumn{2}{|c|}{ Agree } & \multicolumn{2}{|c|}{ Total } \\
\hline & $\mathrm{n}$ & $\%$ & $\mathrm{n}$ & $\%$ & $\mathrm{n}$ & $\%$ & $\mathrm{n}$ & $\%$ \\
\hline Clients are always satisfied with the friendly services offered by health workers & 28 & 10.1 & 0 & 0.0 & 248 & 89.9 & 276 & 100.0 \\
\hline Clients are satisfied with the quality of services we provide & 112 & 40.6 & 0 & 0.0 & 164 & 59.4 & 276 & 100.0 \\
\hline Clients are satisfied with the timeliness of the services & 166 & 60.1 & 28 & 10.1 & 82 & 29.7 & 276 & 99.9 \\
\hline Complaints from stakeholders towards individual health workers are rare & 55 & 19.9 & 83 & 30.1 & 138 & 50.0 & 276 & 100.0 \\
\hline Stakeholders are satisfied with the health workers' cooperation & 84 & 30.4 & 28 & 10.1 & 164 & 59.4 & 276 & 99.9 \\
\hline Health workers clearly know who they serve & 82 & 29.7 & 0 & 0.0 & 194 & 70.3 & 276 & 100.0 \\
\hline $\begin{array}{l}\text { Health workers are always willing to address the clinical and emotional } \\
\text { demands of the patients }\end{array}$ & 55 & 19.9 & 28 & 10.1 & 193 & 69.9 & 276 & 99.9 \\
\hline Health workers get professional support to improve their performance & 56 & 20.3 & 0 & 0.0 & 220 & 79.7 & 276 & 100.0 \\
\hline When at work I know what is expected of me & 0 & 0.0 & 0 & 0.0 & 276 & 100.0 & 276 & 100.0 \\
\hline
\end{tabular}

\section{Productivity of health workers}

Of the health workers, $80.1 \%$ agreed that their skills are suited for the type of work they do. The majority of health workers (79.7\%) indicated that availability of drugs and equipment improves their productivity. Most health workers (70.3\%) indicated that their health facility management encourages them to perform. As many as $60.5 \%$ of workers agreed that they spend most of their time at work attending to the patients and that their productivity is measured according to the number of clients they attend (see Table 4).

A total of $39.5 \%$ of the health workers disagreed that their productivity is measured according to the number of clients they manage and $29.3 \%$ disagreed that they spend most to their time attending to clients, while $10.1 \%$ were undecided. With regard to indicators for measuring performance, $50.4 \%$ of respondents indicated that their organisations do not have indicators for measuring productivity of health workers, $39.9 \%$ agreed, and $9.8 \%$ were uncertain (see Table 4).

Generally, the health workers' self-reporting indicates that they possess adequate skills necessary to perform their jobs. The workers stressed the importance of having adequate supplies of drugs and equipment to support their productivity. The results, however, show that the measurement of productivity of health workers is generally lacking in most health facilities. Much as the health workers have adequate skills, their productivity can be limited by a host of factors like lack of equipment, supplies or drugs, poor management structures and low salaries [22,23]. This study revealed that some health workers (39.5\%) did not seem to understand how their productivity was measured and slightly over half did not know that there were indicators for measuring productivity. There is, therefore, a need to develop and communicate clear indicators for measuring productivity.

\section{Competence of health workers}

All the health workers (100.0\%) indicated that they have mastered the skills necessary to do their work and are confident about their prescribing practices, and all said that they improve their knowledge and skills through continuous professional education, and use their

Table 3 Items concerning the availability of health workers $(n=276)$

\begin{tabular}{|c|c|c|c|c|c|c|c|c|}
\hline \multirow[t]{2}{*}{ Item description } & \multicolumn{2}{|c|}{ Disagree } & \multicolumn{2}{|c|}{ Undecided } & \multicolumn{2}{|c|}{ Agree } & \multicolumn{2}{|c|}{ Total } \\
\hline & $\mathbf{n}$ & $\%$ & $\mathrm{n}$ & $\%$ & $n$ & $\%$ & $\mathbf{n}$ & $\%$ \\
\hline This organisation has a retention policy with clear strategies & 55 & 19.9 & 55 & 19.9 & 166 & 60.1 & 276 & 99.9 \\
\hline I am always available when my services are required & 28 & 10.1 & 0 & 0.0 & 248 & 89.9 & 276 & 100.0 \\
\hline $\begin{array}{l}\text { This facility has adequate numbers of health workers to } \\
\text { deliver the services }\end{array}$ & 138 & 50.0 & 28 & 10.1 & 110 & 39.9 & 276 & 100.0 \\
\hline The rural facilities are as well staffed as the urban ones & 221 & 80.1 & 27 & 9.8 & 28 & 10.1 & 276 & 100.0 \\
\hline $\begin{array}{l}\text { This facility has an attendance register which is filled by } \\
\text { every staff member }\end{array}$ & 27 & 9.8 & 0 & 0.0 & 249 & 90.2 & 276 & 100.0 \\
\hline I am always present during the official working hours & 82 & 29.7 & 28 & 10.1 & 166 & 60.1 & 276 & 100.0 \\
\hline I put in much effort when I am on duty & 27 & 9.8 & 0 & 0.0 & 249 & 90.2 & 276 & 100.0 \\
\hline Staff attendance in this organisation is good & 111 & 40.2 & 0 & 0.0 & 165 & 59.8 & 276 & 100.0 \\
\hline The workload in this facility is manageable & 111 & 40.2 & 56 & 20.3 & 109 & 39.5 & 276 & 100.0 \\
\hline In this facility the patient's waiting-time is short & 109 & 39.5 & 55 & 19.9 & 112 & 40.6 & 276 & 100.0 \\
\hline
\end{tabular}


Table 4 Items concerning the productivity of health workers $(n=276)$

\begin{tabular}{|c|c|c|c|c|c|c|c|c|}
\hline \multirow[t]{2}{*}{ Item description } & \multicolumn{2}{|c|}{ Disagree } & \multicolumn{2}{|c|}{ Undecided } & \multicolumn{2}{|c|}{ Agree } & \multicolumn{2}{|c|}{ Total } \\
\hline & $\mathbf{n}$ & $\%$ & $\mathbf{n}$ & $\%$ & $\mathbf{n}$ & $\%$ & $\mathbf{n}$ & $\%$ \\
\hline $\begin{array}{l}\text { My productivity is measured according to the number of } \\
\text { patients I attend to }\end{array}$ & 109 & 39.5 & 0 & 0.0 & 167 & 60.5 & 276 & 100.0 \\
\hline This organisation has indicators for measuring staff productivity & 139 & 50.4 & 27 & 9.8 & 110 & 39.9 & 276 & 100.1 \\
\hline I spend most of my time attending to patients & 81 & 29.3 & 28 & 10.1 & 167 & 60.5 & 276 & 99.9 \\
\hline My skills are suited for the type of work I do & 28 & 10.1 & 27 & 9.8 & 221 & 80.1 & 276 & 100.0 \\
\hline My productivity is increased by availability of drugs and equipment & 0 & 0.0 & 56 & 20.3 & 220 & 79.7 & 276 & 100.0 \\
\hline $\begin{array}{l}\text { The management structures in this facility encourage the performance } \\
\text { of health workers }\end{array}$ & 54 & 19.6 & 28 & 10.1 & 194 & 70.3 & 276 & 100.0 \\
\hline
\end{tabular}

knowledge and skills to improve the safety of their clients. All health workers (100.0\%) agreed that their attitude towards patient care is good and always make timely referrals of patients in need of further treatment and care (see Table 5).

All the health workers $(100.0 \%)$ indicated that they have good communication skills and are able to use the available technology to support patient care. The majority of health workers (89.9\%) agreed that they are confident about their ability to perform their jobs.

Generally, the results show that the health workers are competent and this is highly likely to enhance their performance. High level of knowledge, skills and abilities among health workers are necessary for effective performance [24]. Health workers also reported that they have good communication skills. This is very important because listening, guidance, clear expectations and feedback are prerequisites for better performance [25]. The health workers in this study reported that they make timely referral when required. This is consistent with findings from a study done in India, where maternal health outcomes improved as a result of good skills in identifying complicated obstetric cases, good counselling and communication skills [26]. The findings of this study however, are contrary to what is reported in Niger, where rural health workers lack the competence to communicate, counsel and convince patients with complications requiring referral to higher level facilities [27].

\section{Behaviour of health workers for performance Proficiency behaviours}

All the health workers (100.0\%) agreed that they communicate openly with each other, coordinate their work amongst themselves and support their co-workers when requested. Most health workers (80.1\%) indicated that they use standard procedures to ensure that their core tasks are properly done while $19.9 \%$ disagreed. Furthermore, $79.9 \%$ of the health workers indicated that they portray a positive image of their organisations and 10.1\% were either in disagreement or uncertain (see Table 6).

Overall, health workers display satisfactory proficiency behaviours that are likely to support good performance. This finding contradicts what was found by a Kenyan study [17], which established that health workers working in hospital paediatric departments were not cooperating and communicating openly with each other and

Table 5 Items concerning the competence of health workers $(n=276$ )

\begin{tabular}{|c|c|c|c|c|c|c|c|c|}
\hline \multirow[t]{2}{*}{ Item description } & \multicolumn{2}{|c|}{ Disagree } & \multicolumn{2}{|c|}{ Undecided } & \multicolumn{2}{|c|}{ Agree } & \multicolumn{2}{|c|}{ Total } \\
\hline & $n$ & $\%$ & $n$ & $\%$ & $\mathbf{n}$ & $\%$ & $n$ & $\%$ \\
\hline I am confident my ability to do my job & 28 & 10.1 & 0 & 0.0 & 248 & 89.9 & 276 & 100.0 \\
\hline I have mastered the skills necessary to perform my job & 0 & 0.0 & 0 & 0.0 & 276 & 100.0 & 276 & 100.0 \\
\hline I am confident about my prescribing practices & 0 & 0.0 & 0 & 0.0 & 276 & 100.0 & 276 & 100.0 \\
\hline $\begin{array}{l}\text { I always improve my knowledge and skills through continuous } \\
\text { professional education }\end{array}$ & 0 & 0.0 & 0 & 0.0 & 276 & 100.0 & 276 & 100.0 \\
\hline My attitude toward the care of patients is good & 0 & 0.0 & 0 & 0.0 & 276 & 100.0 & 276 & 100.0 \\
\hline I use my knowledge and skills to improve safety of patients & 0 & 0.0 & 0 & 0.0 & 276 & 100.0 & 276 & 100.0 \\
\hline $\begin{array}{l}\text { I always make timely referral of patients that are in need of } \\
\text { specialised treatment }\end{array}$ & 0 & 0.0 & 0 & 0.0 & 276 & 100.0 & 276 & 100.0 \\
\hline I have good communication skills & 0 & 0.0 & 0 & 0.0 & 276 & 100.0 & 276 & 100.0 \\
\hline $\begin{array}{l}\text { I am able to use the available communication technology to } \\
\text { support patient care }\end{array}$ & 0 & 0.0 & 0 & 0.0 & 276 & 100.0 & 276 & 100.0 \\
\hline
\end{tabular}


Table 6 Items concerning the individual proficiency behaviours of health workers $(\mathbf{n}=276)$

\begin{tabular}{|c|c|c|c|c|c|c|c|c|}
\hline \multirow[t]{2}{*}{ Item description } & \multicolumn{2}{|c|}{ Disagree } & \multicolumn{2}{|c|}{ Undecided } & \multicolumn{2}{|c|}{ Agree } & \multicolumn{2}{|c|}{ Total } \\
\hline & $\mathrm{n}$ & $\%$ & $\mathrm{n}$ & $\%$ & $\mathrm{n}$ & $\%$ & $\mathrm{n}$ & $\%$ \\
\hline $\begin{array}{l}\text { I always use standard procedures to ensure that } \\
\text { my core tasks are completed properly }\end{array}$ & 55 & 19.9 & 0 & 0.0 & 221 & 50.4 & 276 & 100.0 \\
\hline I coordinate my work with my co-workers & 0 & 0.0 & 0 & 0.0 & 276 & 50.7 & 276 & 100.0 \\
\hline I communicate openly with my co-workers & 0 & 0.0 & 0 & 0.0 & 276 & 100.0 & 276 & 100.0 \\
\hline I provide help to my co-workers when asked & 0 & 0.0 & 0 & 0.0 & 276 & 100.0 & 276 & 100.0 \\
\hline $\begin{array}{l}\text { I portray a positive image of my organisation to } \\
\text { others such as the patients }\end{array}$ & 28 & 10.1 & 28 & 10.1 & 220 & 79.7 & 276 & 99.9 \\
\hline
\end{tabular}

this was affecting their performance and the quality of care given to patients. Some researchers have established that behaviours that involve cooperation, creativity and self-development contribute to job performance [28]. Additionally, role clarity is known to be one of the strongest predictors of individual, team, and task organisational proficiency behaviours for performance [29].

\section{Adaptive behaviours}

All health workers $(100.0 \%)$ agreed that they adjust well to changes in their core tasks and have learned new skills to help them adjust to change. Most health workers $(89.9 \%)$ indicated that they are flexible with regard to the overall changes within their organisations and 10.1\% disagreed. Similarly, $80.1 \%$ of the health workers agreed that they respond constructively to changes in the way their teams work (see Table 7).

These results indicate that the health workers display positive individual adaptive behaviours, which can contribute to good performance. This is contrary to what was found in Kenya where health workers were reported to have inadequacies in adapting or responding to new clinical practices or guidelines due to lack of perceived benefits linked to their uptake [17]. In that study, senior and older health workers were often reported to be stuck in the patterns of previous clinical practice although there were some exceptions [17]. This problem was attributed to the lack of experience in being compelled to change by emerging knowledge. Openness to change is known to be a strong predictor for adaptive behaviour. This can enhance task performance for an individual, teams and the organisation as a whole [29].

\section{Proactive behaviours}

From Table 8, it is clear that all health workers (100.0\%) indicated that that they have initiated better ways of performing their core tasks. A large proportion of health workers $(90.2 \%)$ agreed that they have developed new and improved methods to help their work units or teams perform better and $9.8 \%$ disagreed. Of the health workers, $80.1 \%$ indicated that they have made suggestions to improve the overall performance of their organisations, $10.1 \%$ were undecided and $9.8 \%$ disagreed.

The results clearly indicate that the health workers are proactive and this is likely to enhance their performance. Some studies report that workers who score highly on creative performance or are proactive achieve high outcomes in innovative effectiveness [28]. This is good for individual, team, and organisational performance. Proactive behaviours ensure that the whole organisation develops rather than only individual departments [29].

\section{Client-oriented behaviours}

Table 9 shows that all health workers $(100.0 \%)$ are aware of their task of serving the clients, have the clients' interest in mind and respect their clients' opinions. All the health workers $(100.0 \%)$ indicated that they always behave professionally, take a problem-solving approach to care for their clients and give their clients opportunity to express their needs. The majority of health workers (99.3\%) agreed that they try to assess their clients' needs and $90.2 \%$ have respect for their clients. Ninety percent of the health workers indicated that they always take time to perform their clinical duties and try to address their clients' needs with the appropriate treatment available.

Table 7 Items concerning the adaptive behaviours of health workers $(\mathbf{n}=\mathbf{2 7 6})$

\begin{tabular}{|c|c|c|c|c|c|c|c|c|}
\hline \multirow[t]{2}{*}{ Item description } & \multicolumn{2}{|c|}{ Disagree } & \multicolumn{2}{|c|}{ Undecided } & \multicolumn{2}{|c|}{ Agree } & \multicolumn{2}{|c|}{ Total } \\
\hline & $\mathbf{n}$ & $\%$ & $\mathbf{n}$ & $\%$ & $\mathbf{n}$ & $\%$ & $\mathbf{n}$ & $\%$ \\
\hline I adjust well to changes in my core tasks & 0 & 0.0 & 0 & 0.0 & 276 & 100.0 & 276 & 100.0 \\
\hline I have learned new skills to help me adjust to changes in my core tasks & 0 & 0.0 & 0 & 0.0 & 276 & 100.0 & 276 & 100.0 \\
\hline I respond constructively to changes in the way my team works & 55 & 19.9 & 0 & 0.0 & 221 & 80.1 & 276 & 100.0 \\
\hline I am flexible with regard to the overall changes in my organisation & 28 & 10.1 & 0 & 0.0 & 248 & 89.9 & 276 & 100.0 \\
\hline
\end{tabular}


Table 8 Items for individual proactive behaviours $(\mathbf{n}=\mathbf{2 7 6})$

\begin{tabular}{|c|c|c|c|c|c|c|c|c|}
\hline \multirow[t]{2}{*}{ Item description } & \multicolumn{2}{|c|}{ Disagree } & \multicolumn{2}{|c|}{ Undecided } & \multicolumn{2}{|c|}{ Agree } & \multicolumn{2}{|c|}{ Total } \\
\hline & $\mathrm{n}$ & $\%$ & $\mathbf{n}$ & $\%$ & $\mathrm{n}$ & $\%$ & $\mathbf{n}$ & $\%$ \\
\hline I have initiated better ways of performing my core tasks & 0 & 0.0 & 0 & 0.0 & 276 & 100.0 & 276 & 100.0 \\
\hline $\begin{array}{l}\text { I have developed new and improved methods to help my } \\
\text { work unit perform better }\end{array}$ & 27 & 9.8 & 0 & 0.0 & 249 & 90.2 & 276 & 100.0 \\
\hline $\begin{array}{l}\text { I have made suggestions to improve the overall performance } \\
\text { of the organisation }\end{array}$ & 27 & 9.8 & 28 & 10.1 & 221 & 80.1 & 276 & 100.0 \\
\hline
\end{tabular}

These results demonstrate that health workers are generally inclined to display client-oriented behaviours. Client-oriented behaviours include attributes such as empathy, assurance, responsiveness, authenticity, listening, dedication and civility which the health workers in this study seem to display [30]. The behaviours of health workers such as doctors, nurses and clinical officers are critical to both patient satisfaction and successful health outcomes.

\section{Correlation between individual performance behaviours and performance of health workers}

The results show that individual performance behaviours are positively related to the dimensions of performance. There is a significant and high positive correlation between responsiveness and the individual proficiency behaviours of health workers $(r s=0.856 ; P<0.01)$. There are also significant and moderate correlations between individual client-oriented behaviours $(r s=0.669$; $P<0.01$ ), individual adaptive behaviours $(r s=0.623 ; P<$ $0.01)$, individual proactive behaviours $(r s=0.598 ; P<$ 0.01 ) and the responsiveness of health workers. Indeed there is a high likelihood that health workers who are highly proficient, client-oriented and display adaptive and proactive behaviours, will demonstrate high responsiveness towards clients. The individual workers' behaviours that involve teamwork, innovativeness and selfadvancement contribute to performance [28] (see Table 10).
The results also indicate significant and high positive correlation between the individual proactive behaviours ( $r s=0.759 ; P<0.01$ ), individual proficiency behaviours ( $r s=0.724 ; P<0.01)$ and the availability of health workers. There is significant and moderate correlation between the individual adaptive behaviours $(r s=0.659 ; P<$ 0.01 ), individual client oriented behaviours ( $r s=0.537$; $P<0.01)$ and the availability of health workers. This demonstrates that proactive and proficient individuals are likely to be available to perform their duties. There is significant but low positive correlation between individual client-oriented behaviours, $(r s=0.396 ; P<0.01)$, individual adaptive behaviours ( $r s=0.343 ; P<0.01)$, individual proactive behaviours ( $r s=0.262 ; P<0.01$ ), individual proficiency behaviours $(r s=0.235 ; P<0.01)$ and the productivity of health workers. Indeed while adaptive, proactive and proficiency behaviours may facilitate individual productivity; it is not always certain that this will be the case (see Table 10).

The results in Table 10 further show that there are significant and moderate correlations between the individual adaptive behaviours ( $r s=0.643 ; P<0.01$ ), individual proficiency behaviours $(r s=0.562 ; P<0.01)$ and the competence of health workers. There are also significant but low correlations between the individual clientoriented behaviours ( $r s=0.449 ; P<0.01)$, individual proactive behaviours $(r s=0.359 ; P<0.01)$ and competence of health workers. This can be interpreted as follows: adaptive and proficient health workers are highly

Table 9 Items concerning client-oriented behaviour $(\mathbf{n}=\mathbf{2 7 6}$ )

\begin{tabular}{|c|c|c|c|c|c|c|c|c|}
\hline \multirow[t]{2}{*}{ Item description } & \multicolumn{2}{|c|}{ Disagree } & \multicolumn{2}{|c|}{ Undecided } & \multicolumn{2}{|c|}{ Agree } & \multicolumn{2}{|c|}{ Total } \\
\hline & $\mathbf{n}$ & $\%$ & $\mathbf{n}$ & $\%$ & $\mathbf{n}$ & $\%$ & $\mathbf{n}$ & $\%$ \\
\hline I try to assess what the clients' needs are & 0 & 0.0 & 2 & 0.7 & 274 & 99.3 & 276 & 100.0 \\
\hline I have the clients best interest in mind & 0 & 0.0 & 0 & 0.0 & 276 & 100.0 & 276 & 100.0 \\
\hline I try to address the clients' needs with the appropriate treatment available & 0 & 0.0 & 28 & 10.1 & 248 & 89.9 & 276 & 100.0 \\
\hline I am aware that my task is to serve my clients to the best of my ability & 0 & 0.0 & 0 & 0.0 & 276 & 100.0 & 276 & 100.0 \\
\hline I respect what the patients have to say & 0 & 0.0 & 0 & 0.0 & 276 & 100.0 & 276 & 100.0 \\
\hline I have respect for my clients & 27 & 9.8 & 0 & 0.0 & 249 & 90.2 & 276 & 100.0 \\
\hline I give clients opportunity to express their needs with me & 0 & 0.0 & 0 & 0.0 & 276 & 100.0 & 276 & 100.0 \\
\hline I take a problem-solving approach to care for my clients & 0 & 0.0 & 0 & 0.0 & 276 & 100.0 & 276 & 100.0 \\
\hline I always take time to perform my clinical work & 28 & 10.1 & 0 & 0.0 & 248 & 89.9 & 276 & 100.0 \\
\hline I always behave in a professional manner & 0 & 0.0 & 0 & 0.0 & 276 & 100.0 & 276 & 100.0 \\
\hline
\end{tabular}


Table 10 Correlation between the individual performance behaviours and the dimensions of performance $(n=276)$

\begin{tabular}{|c|c|c|c|c|c|}
\hline Spearman's rho rank order non-parametric correlations & & Responsiveness & Availability & Productivity & Competence \\
\hline \multirow[t]{3}{*}{ Individual proficiency behaviours } & Correlation & $0.856^{* *}$ & $0.724^{* *}$ & $0.235^{* *}$ & $0.562^{* *}$ \\
\hline & Sig (2-tailed) & 0.000 & 0.000 & 0.000 & 0.000 \\
\hline & $\bar{N}$ & 276 & 276 & 276 & 276 \\
\hline \multirow[t]{3}{*}{ Individual adaptive behaviours } & Correlation & $0.623^{* *}$ & $0.659^{* *}$ & $0.343^{* *}$ & $0.643 * *$ \\
\hline & Sig (2-tailed) & 0.000 & 0.000 & 0.000 & 0.000 \\
\hline & $\bar{N}$ & 276 & 276 & 276 & 276 \\
\hline \multirow[t]{3}{*}{ Individual proactive behaviours } & Correlation & $0.598^{* *}$ & $0.759^{* *}$ & $0.262^{* *}$ & $0.359^{* *}$ \\
\hline & Sig (2-tailed) & 0.000 & 0.000 & 0.000 & 0.000 \\
\hline & $\mathrm{N}$ & 276 & 276 & 276 & 276 \\
\hline \multirow[t]{3}{*}{ Individual client-oriented behaviours } & Correlation & $0.669^{* *}$ & $0.537^{* *}$ & $0.396^{* *}$ & $0.449^{* *}$ \\
\hline & Sig (2-tailed) & 0.000 & 0.000 & 0.000 & 0.000 \\
\hline & $\bar{N}$ & 276 & 276 & 276 & 276 \\
\hline
\end{tabular}

**Correlation is significant (Sig) at the 0.01 level (2-tailed).

likely to be competent but this may not always hold since competent health workers may not always be adaptive. The workers who score highly on creative performance are likely to achieve high outcomes in creative effectiveness [28].

\section{Conclusion}

This research uncovered that the health workers under study possessed considerable degrees of the four performance measures (responsiveness, availability, productivity and competence). This indicates that the respondents understand and are capable of performing according to their clients as well as their organisations' expectations, which is providing quality health care. Despite this, the reality is that the health workers often fall short of the stakeholders' expectations because of factors beyond their control. These include organisational factors such as lack of adequate supplies of drugs and equipment. Even more inhibiting is the lack of professional support reported by some respondents as this is vital to maintaining spirit of high performance even when circumstances are not so favourable, especially in the decentralised facilities.

There is a need to put in place a mechanism for timely management of the clients. By so doing, the responsiveness of health services is likely to be enhanced. In addition the local governments should put in place an efficient mechanism for attracting and retaining health workers especially for the rural areas. This can be done through provision of housing in the rural facilities and possibly by introducing a hardship allowance. Lastly, the Ministry of Health has to set clear indicators for measuring the productivity of the health workers and these should be communicated to all stakeholders in the health sector. This will likely improve accountability, which is one of the key elements of decentralisation.
By implications, all stakeholders need to work together to support the performance of health workers if desired health outcomes are to be attained. The central government needs to exercise full fiscal decentralisation to empower local governments and facilities so that they can provide health workers with adequate supplies and training.

\section{Abbreviations}

HSSP: Health Sector Strategic Plan; IMCI: Integrated Management of Childhood IIInesses; MDGs: Millennium Development goals; Rs: Spearman rho correlation; SPSS: Statistical Package for Social Sciences; TB: Tuberculosis; UNCST: Uganda National Council for Science and Technology; VHTs: Village Health Teams; WHO: World Health Organization.

\section{Competing interests}

The authors declare no competing interests.

\section{Authors' contributions}

GWL conducted the study for his Doctoral thesis; JHR and BLD were the advisors for this study. GWL obtained permission for the study, collected, analysed and interpreted the data. JHR and BLD provided the overall supervision of this study right from its inception to its conclusion. GWL wrote the first draft of the article. Both JHR and BLD critically reviewed and contributed substantially to the article and continued with the process until publication. All authors read and approved the final manuscript.

\section{Acknowledgements}

We would like to acknowledge the health workers that participated in this study and Ms Jane M Jonkomane who edited the manuscript.

\section{Author details}

${ }^{1}$ Graduate, Department of Health Studies, Unisa \& IMA World Health Sudd Health Project, IMA World Health, 500 Main Street, PO Box 429, New Windsor, MD 21776, USA. ²Department of Health Studies, PO Box 392, Pretoria Unisa 0003, South Africa.

Received: 27 February 2012 Accepted: 22 October 2012

Published: 7 November 2012

\section{References}

1. World Health Organization: Working together for Health: World Health Report. Geneva: World Health Organization; 2006.

2. Global Health Workforce A: Health Workers for All and All for Health Workers, The Kampala Declaration and Agenda for Global Action. 2008. http://www. who.int/entity/workforcealliance/forum/1_agenda4GAction_final.pdf. 
3. Jeppsson A, Okuonzi SA: Vertical or holistic decentralisation of the health sector? Experiences from Zambia and Uganda. Int J Health Plann Manage 2000, 15:273-289.

4. Kisubi M: The process of decentralisation. In Post-Conflict Uganda: towards an effective civil service. Edited by Langseth P, Mujaju J. Kampala: Fountain Publishers; 1996:83-106.

5. Pariyo GW, Ekirapa-Kiracho E, Okui O, Rahman MH, Peterson S, Bishai DM, Lucas $\mathrm{H}$, Peters $\mathrm{DH}$ : Changes in utilisation of health services among poor and rural residents in Uganda: are reforms benefiting the poor? International Journal for Equity in Health 2009, 8:39. http://www. equityhealthj.com/content/8/1/39.

6. Kavuma RM: Uganda's health care system explained. The Guardian News and Media Limited 2009, http://www.guardian.co.uk.

7. Ministry of Health Uganda: Health Sector Strategic Plan III: 2010/11-2014/15. Kampala: Government of Uganda; 2010. http://www.health.go.ug/docs/ HSSP_III2010.pdf.

8. Ministry of Health Uganda: Annual health sector performance report: financial year 2007/2008. Kampala: Government of Uganda; 2008. http://health.go.ug/ mohweb/?page_id=176.

9. Lirri E: Decentralisation blamed for poor health services. The Daily Monitor Online 2008, http://www.monitor.co.ug/artman/publish/regional-special.

10. Fanaka Kwa W: Uganda health sector: an overview. Policy paper on health sector financing in Uganda. Fanaka Kwa Wote Newsletters 2008, 1:1. http://www.kwawote.org.

11. Polit DF, Beck CT: Nursing research: generating and assessing evidence for nursing practice. 8th edition. Philadelphia: Lippincott Williams \& Wilkins; 2008.

12. Saunders $M$, Lewis $P$, Thornhill $A$ : Research methods for business students. 5th edition. Harlow: FT Prentice Hall; 2009.

13. Jamieson S: Likert scales: how to ab(use) them. Med Educ 2004, 38:1217-1218.

14. George D, Mallery P: SPSS for Windows step by step: a simple guide and reference. 11.0 update. 4th edition. Boston: Allyn \& Bacon; 2003.

15. Department for International Development (DFID): Health workers' role in responding to the needs of the poor. In Briefing: A DFID Practice Paper. London: DFID Health Resource Centre; 2006:1-9. http://www. hrhresourcecenter.org/node/3059.

16. Heizer J, Render B: Operations Management. 9th edition. New Jersey: Prentice Hall; 2008.

17. Nzinga J, Mbindyo P, Mbaabu L, Warira A, English M: Documenting the experiences of health workers expected to implement guidelines during an intervention study in Kenyan Hospitals. Implementation Science 2009, 4:44. http://www.implementationscience.com/content/4/1/44.

18. Freedman LP: Achieving the MDGs: health systems as core social institutions. Development 2005, 45:19-24.

19. Huicho L, Dieleman M, Campbell J, Codjia L, Balabanova D, Dussault G, Dolea C: Increasing access to health workers in underserved areas: a conceptual framework for measuring results. Bull World Health Organ 2010, 88:357-363.

20. Joint Learning Initiative (JLI): Human resources for health: overcoming the crisis. Cambridge: Global Equity Initiative/Harvard University Press; 2004. http://www.globalhealthtrust.org/report.

21. Padarath A, Chamberlain C, McCoy A, Ntuli A, Rowson M, Loewenson R: Health Personnel in Southern Africa: Confronting maldistribution and brain drain. In EQUINET Discussion Paper. 3rd edition. Edited by Loewenson R, Thompson C.: East and Southern Africa Region Harare; EQUINET, Health Systems Trust (South Africa) and MEDACT (UK); 2003:6-9. http://ww.medact. org/content/health/documents/brain_drain/Padarath\%20et\%20al.\%20-\% 20Medact-HST-Equient.pdf.

22. Dieleman M, Harnmeijer JW: Improving health worker performance: in search of promising practices. Geneva: World Health Organization; 2006.

23. Hagopian A, Zuyderduin A, Kyobutungi N, Yumkella F: Job satisfaction and morale in the Ugandan health workforce. Health Aff 2009, 28:w863-w875.

24. Liu Y, Combs JG, Ketchen DJ Jr, Ireland RD: The Value of human resource management for organisational performance. Bus Horiz 2007, 50:503-511.

25. Huang L, Chen L, Tsai HC, Lin CJ: Development of an instrument for assessing factors related to nurses' organisation commitment. Mid Taiwan Journal of Medicine 2006, 11:9-19.

26. lyengar K, lyengar SD: Emergency obstetric care and referral: experience of two midwife-led health centres in rural Rajasthan, India. Reprod Health Matter 2009, 17:9-20.
27. Bossyns $P$, Van Lerberghe $W$ : The weakest link: competence and prestige as a constraint to referral by isolated nurses in rural Niger. Human Resource for Health 2004, 2:1. http://www.human-resources-health.com/ content/2/1/1.

28. Kahya E: The effects of job performance on effectiveness. Int J Ind Ergon 2009, 39:96-104.

29. Griffin MA, Neal A, Parker SK: A new model of work role performance: positive behaviour in uncertain and interdependent contexts. Acad Manage J 2007, 50:327-347.

30. Lanjananda P, Patterson PG: Determinants of customer-oriented behaviour in a health care context. J Serv Manag 2009, 20:5-32.

doi:10.1186/1478-4491-10-41

Cite this article as: Lutwama et al:: A descriptive study on health workforce performance after decentralisation of health services in Uganda. Human Resources for Health 2012 10:41.

\section{Submit your next manuscript to BioMed Central and take full advantage of:}

- Convenient online submission

- Thorough peer review

- No space constraints or color figure charges

- Immediate publication on acceptance

- Inclusion in PubMed, CAS, Scopus and Google Scholar

- Research which is freely available for redistribution

Submit your manuscript at www.biomedcentral.com/submit
C) Biomed Central 